${ }^{8}$ Von Rosen S. Early diagnosis and treatment of congenital dislocation of the hip joint. Acta Orthopaedica Scandinavica 1956;26:136-40.

${ }^{9}$ Barlow TG. Early diagnosis and treatment of congenital dislocation of the hip. F Bone Foint Surg 1962;44B:292-310.

10 Coleman S. Diagnosis of congenital dysplasia of the hip in the newborn infant. $\mathcal{F} A M A$ 1956;162:548-52.

11 Palmen K. Diagnosis of congenital dislocation of the hip-joint in Sweden during 1948-1960. Acta Paediatrica Scandinavica 1961;50, suppl:129.

12 Anonymous. Detecting the dislocated hip. Lancet 1977;ii:909-10.

${ }^{13}$ Freidensborg $\mathrm{N}$. The effect of early diagnosis of congenital dislocation of the hip. Acta Paediatrica Scandinavica 1976;65:323-8.

14 Bjerkreim I. Congenital dislocation of the hip joint in Norway. Acta Orthopaedica Scandinavica 1974; 157 Suppl.

15 Royal College of General Practitioners. Trends in national morbidity. f R Coll Gen Pract 1976;26:Occasional paper No 3.
16 Wilkinson JA, Howell CJ. Management of infants with congenital W displacement of the hip. Proc R Soc Med 1973;66:239-40.

17 Macfarlane A. Congenital dislocation of the hip-an epidemiological conundrum. F Mat Child Health 1980;5:13-5.

18 Khingberg MA, Chen R, Chemke J, Levin G. Rising rates of congenital dislocation of the hip. Lancet 1976;i:298.

19 Center for Disease Control. Congenital malformations surveillance report. Atlanta, Georgia: Center for Disease Control, 1975.

${ }^{20}$ Lehman ECH, Street DG. Neonatal screening in Vancouver for congenital dislocation of the hip. Can Med F 1981;124:1003-8.

21 Wilkinson JA. A post-natal survey for congenital displacement of the hip. F Bone foint Surg 1972;54B :40-9.

(Accepted 9 September 1982)

\title{
Admission after mild head injury: benefits and costs
}

\author{
A D MENDELOW, D A CAMPBELL, R R JEFFREY, J D MILLER, C HESSETT, \\ J BRYDEN, B JENNETT
}

\begin{abstract}
Large numbers of patients are admitted to hospital in Britain after mild head injury in the hope of anticipating complications. Investigation of 1442 consecutive admissions with head injury to the Edinburgh Royal Infirmary yielded 56 intracranial haematomas. Of 865 patients who were alert and orientated in the accident and emergency department after having been briefly knocked out but who had no skull fracture, no focal neurological signs, and no history of headache or vomiting, only one developed an intracranial haematoma. In deciding which patients should be admitted a skull fracture is a much more important risk factor than is a history of brief unconsciousness. If criteria for admission took account of this fewer patients would be admitted and the savings would be considerable.
\end{abstract}

\section{Introduction}

Head injury is common in Britain. More than a million patients attend accident and emergency departments each year; most of these patients are sent home, but more than 100000 a year are admitted to hospital. ${ }^{1}$ The number of admissions for head injury has been increasing since 1961 although the number of fatal and serious injuries has been falling since 1968." The additional admissions are patients with mild injuries who are discharged within two days. Only $5 \%$ of patients admitted to hospital after head injury in England and Wales reach a regional neurosurgical unit, usually by secondary transfer; however, this proportion

Head and Spinal Injury Unit, Department of Neurology, Edinburgh Royal Infirmary, Edinburgh EH3 9YW

A D MENDELOW, PHD, FRCS, senior lecturer in neurosurgery

D A CAMPBELL, FRCS, senior registrar in neurosurgery

R R JEFFREY, FRCS, senior registrar in accident and emergency surgery

J D MILLER, MD, FRCS, professor of surgical neurology

MRC Head Injury Research Programme, Department of Neurosurgery, Institute of Neurological Sciences, Glasgow G51 4TF

C HESSETT, BSC, MSC, research assistant

J BRYDEN, FFCM, MSC, consultant epidemiologist

B JENNETT, MD, FRCS, professor of neurosurgery varies from $0.5 \%$ to $35 \%$ in different places. ${ }^{3}$ The purpose of $\mathcal{E}^{\circ}$ initial admission, and also of subsequent transfer, is to reduce avoidable morbidity and mortality, which is mainly due to $N$ delayed recognition and treatment of acute intracranial haematomas. ${ }^{4}$ It has been suggested that more of the admitted patients should be transferred to neurosurgical units, especially since computed tomography has become available, ${ }^{5}$ and that they should be sent there sooner. It has also been proposed that fewer of the patients presenting at accident and emergency departments after head injury need be admitted. ${ }^{6}$

For some years in Edinburgh patients with mild head injuries have been dealt with differently from the rest of Britain in that they are admitted directly to a ward which is under the care of neurosurgeons. We report here a consecutive series of admissions with head injury to the Edinburgh head injury unit, review admission policies for mild injuries, and comment on some aspects of the costs incurred.

\section{Patients and methods}

The hospital records of patients discharged from the head and spinal injury unit at the Edinburgh Royal Infirmary in 1979 were reviewed. Of 1593 admissions, 1442 had head injuries. Most (1297, $90^{\prime \prime}$ ) had been admitted directly from the accident and emergency department of the Royal Infirmary; the remainder were referred secondarily from outside hospitals. This report deals mainly with the group of direct admissions, which correspond to patients who are 을 admitted to primary surgical wards elsewhere. Cases were assigned to $\mathrm{N}$ five broad diagnostic categories which were mutually exclusive: $(a)$ o haematoma-any intracranial haematoma requiring operation; $(b)$ I severe head injury-head injury producing confusion and amnesia lasting 24 hours but not due to an intracranial haematoma; (c) $N$ concussion-patients with post-traumatic amnesia lasting $<24$ hours, N including patients who were alert and orientated on admission; $(d)$ other cases of skull fracture, linear or depressed, of the vault or the base (not already in categories $(a),(b)$, or $(c)$ ); and $(e)$ other head injuries.

\section{Results}

The 1297 patients admitted directly to the Edinburgh unit had similar characteristics to patients admitted to other primary surgical $\unrhd$ wards in Scotland (table I); there were, however, fewer children in the Edinburgh unit and the Glasgow general hospital since both of these areas are served by independent children's hospitals. Also, $\frac{0}{0}$ multiple injuries were less frequently admitted to the Edinburgh unit. 
TABLE I-Features of direct admissions to Edinburgh neurosurgical unit and of admissions to primary surgical wards elsewhere in Scotland

\begin{tabular}{|c|c|c|c|}
\hline & \multirow[b]{2}{*}{$\begin{array}{c}\text { Direct } \\
\text { admissions } \\
\text { in Edinburgh ("., } \\
(\mathrm{n}=1297)\end{array}$} & \multicolumn{2}{|c|}{ Admissions to: } \\
\hline & & $\begin{array}{c}\text { Glasgow } \\
\text { General } \\
\text { Hospital (" }(1)^{12} \\
(\mathrm{n}=918)\end{array}$ & $\begin{array}{c}\text { Scottish } \\
\text { primary } \\
\text { surgical } \\
\text { wards }\left("{ }^{\prime}(1)\right)^{9} \\
(\mathrm{n}=1181)\end{array}$ \\
\hline Age 15 years & 12 & 7 & 36 \\
\hline admission & 76 & 73 & 79 \\
\hline Skull fracture & 11 & 8 & 7 \\
\hline $\begin{array}{l}\text { Alcohol intoxication } \\
\text { (clinical evidence) }\end{array}$ & 42 & 55 & 30 \\
\hline $\begin{array}{l}\text { Multiple injury } \\
\text { M }\end{array}$ & $\begin{array}{l}42 \\
13\end{array}$ & 21 & 27 \\
\hline Intracranial haematoma & 2 & i & 1 \\
\hline $\begin{array}{l}\text { Mortality } \\
\text { "Talk and die" rate }\end{array}$ & 3 & 2 & 1 \\
\hline $\begin{array}{l}\text { "Talk and die" rate } \\
(" \text { " of deaths) }\end{array}$ & 19 & 31 & 19 \\
\hline
\end{tabular}

TABLE II-Diagnostic groups* with percentage within each population

\begin{tabular}{lcc}
\hline Discharge diagnosis & $\begin{array}{c}\text { "of all } \\
\text { admissions }\end{array}$ & $\begin{array}{c}\text { " of all direct } \\
\text { admissions }\end{array}$ \\
\hline Concussion & 83 & 87 \\
Haematoma & $3 \cdot 9$ & $2 \cdot 1$ \\
Fractures & $7 \cdot 0$ & $5 \cdot 8$ \\
Basal (rhinorrhoea and otorrhoca) & $1 \cdot 9$ & $1 \cdot 9$ \\
Depressed (compound and non-compound) & $1 \cdot 1$ & $0 \cdot 8$ \\
Vault (not in other diagnostic groups) & $4 \cdot 0$ & $3 \cdot 0$ \\
Severe head injury & $2 \cdot 8$ & $2 \cdot 0$ \\
Other head injury & $3 \cdot 7$ & $3 \cdot 4$ \\
\hline
\end{tabular}

* Diagnostic groups are exclusive (see text).

TABLE III-Reasons for admission and features for each population

\begin{tabular}{lcc}
\hline & $\begin{array}{c}\text { "., of all direct } \\
\text { admissions } \\
(\mathrm{n}=1297)\end{array}$ & $\begin{array}{c}\text { "., of all } \\
\text { admissions } \\
(\mathrm{n}=1442)\end{array}$ \\
\hline Reasons for admission: & & \\
Knocked out & 79 & 74 \\
Skull fracture & 1 & 1 \\
Focal signs & 1 & 2 \\
Depressed consciousness & 3 & 4 \\
Any combination of the above (including & 16 & 19 \\
other) & 13 & 14 \\
Multiple injuries & 3 & 4 \\
Death rate & 11 & 14 \\
Skull fracture & 2 & 5 \\
Computed tomography scan & 19 & 20 \\
\hline "Talk and die" rate & & \\
\hline
\end{tabular}

The vast majority of these 1297 patients had minor head injuries, $87 \%$ being categorised as concussion (table II); most had been admitted principally because they had been briefly knocked out (table III). Only $11^{\circ}$ o of the directly admitted patients had a skull fracture, but this was found much more frequently in the groups with haematoma and severe head injury (table IV). Of 56 intracranial haematomas confirmed surgically, seven were extradural (no mortality) and 49 intradural (mortality $\left.29^{\prime \prime}\right)$ ). Twenty-six of the 56 patients with haematomas had been admitted directly from the accident and emergency department. Only two of the seven patients with extradural haematomas had been admitted directly. Eleven of the $56(20 \%)$ patients with intracranial haematomas were alert and orientated on admission (table V); of these, four were transferred from outside hospitals, all of them having a skull fracture. The reasons for the direct admission of the seven patients who were alert and orientated and who subsequently developed haematomas were: focal signs in two, headache in two, skull fracture in one, and vomiting in one (figure). The seventh patient had none of these features but did have a short period of amnesia after the accident. None of the other six patients who were alert and orientated when admitted had a history of amnesia. There were 865 patients admitted directly in an alert and orientated state with no skull fracture, no focal signs, no history of headache or vomiting, but with a history of being knocked out; of these patients only one developed an intracranial haematoma.

Length of stay in hospital-To assess the bed usage by directly admitting patients with mild head injuries into a neurosurgical unit we calculated for each diagnostic category the number of patients and the mean duration of stay (table VI). Although patients with concussion accounted for almost $90 \%$ of admissions, the aggregate bed days occupied by these patients was less than half of the total. On an estimated notional daily cost of $£ 60$ during 1979 for patients in the head injury unit in the Royal Infirmary, Edinburgh, ${ }^{7}$ the cost of patients admitted with concussion would have been $£ 117567$, which

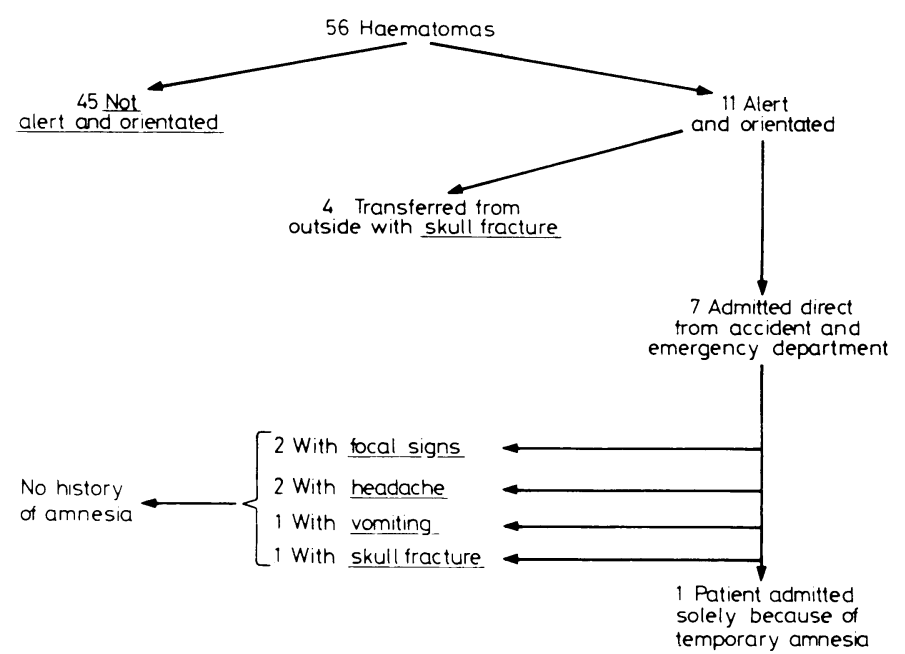

Reasons for admission in 56 patients with haematomas.

TABLE IV-Radiological skull fractures in the different groups ( $n=1442$ )

\begin{tabular}{lrc}
\hline & No & $\begin{array}{c}\text { o. With } \\
\text { fracture }\end{array}$ \\
\hline All admissions & 1442 & 14 \\
Diagnostic category: & 1190 & 3 \\
$\quad$ Concussion & 56 & 47 \\
Haematoma & 41 & 66 \\
Severe head injury & 54 & 28 \\
Other head injury & 1297 & 11 \\
Type of referral: & 140 & 39 \\
Direct & \\
Transfer* & & \\
\hline
\end{tabular}

* In five patients the source of referral was uncertain.

TABLE V-Admission characteristics of the patients who developed intracranial haematomas

\begin{tabular}{lrr}
\hline & No & \\
\hline Alert and orientated & 11 & 20 \\
Reasons for admission: & 2 & 4 \\
Knocked out & 2 & 4 \\
Focal signs & 2 & 4 \\
Skull fracture & 13 & 23 \\
Skull fracture +other reasons for admission & 13 & 23 \\
Depressed consciousness & 3 & 5 \\
Headache or vomiting or both & 21 & 38 \\
Other combinations or reasons for admission or both & 26 & 47 \\
Skull fracture & 30 & 54 \\
\hline Computed tomography scan & 56 & 100 \\
\hline Total & & \\
\hline
\end{tabular}

TABLE VI-Length of stay* in head and spinal injury unit, Edinburgh

\begin{tabular}{lcc}
\hline Diagnostic category & $\begin{array}{c}\text { Mean length } \\
\text { of stay (days) }\end{array}$ & $\begin{array}{c}\text { Total patient } \\
\text { days }\end{array}$ \\
\hline Concussion & $1 \cdot 6$ & 1959 \\
Haematoma & $25 \cdot 4$ & 1423 \\
Fractures & $7 \cdot 8$ & 783 \\
Severe head injury & 20.5 & 841 \\
Other head injury & $5 \cdot 2$ & 282 \\
\hline Total & $3 \cdot 7$ & 5288 \\
\hline
\end{tabular}

* Excluding stay in referring hospitals before and after period in unit. 
is $37 \%$ of the total cost for all head injuries ( $£ 317280$ ). The cost of observing for one day the 865 patients who had been briefly knocked out but who had no other risk factor was $£ 51900(865 \times 60 \times 1)$; this led to the identification of one patient with an intracranial haematoma. If the period of observation was extended beyond one day the cost would have been greater. Similarly, the cost would have been $£ 73525$ if 1982 prices ( $£ 85$ a day) had been used. ${ }^{8}$

\section{Discussion}

It has long been taught that a brief period of unconsciousness or amnesia is a risk factor for the development of intracranial haematoma. This appears to be the basis of the widespread policy in Britain of admitting to hospital for observation all patients with such a history. The survey of head injuries in primary surgical wards of Scottish hospitals showed that $76 \%$ of patients had no signs or symptoms when admitted, nor a skull fracture; more than three-quarters of these patients stayed less than two days if they had no extracranial injuries. ${ }^{9}$ What the present study shows is that patients of this kind very rarely develop an intracranial haematoma. For the one patient out of 865 who did develop an intracranial haematoma the cost was f51 900. A much better predictor of the likely development of an intracranial haematoma was the presence of a fracture of the skull. This is particularly valuable in patients in accident and emergency departments who are alert and who do not have clinical features which would be likely to lead to their admission, since the fracture may be the only index of the severity of the blow. Evidence from more than one source indicates that in such patients the risk that an acute intracranial haematoma will develop is increased by 300 -fold to 400 -fold if there is a skull fracture. ${ }^{10}$ A national study by the Royal College of Radiologists ${ }^{11}$ estimated that the radiological cost of identifying one patient (with intracranial haematoma from a group of 4800 head injuries in accident and emergency departments) was $£ 43200$. This was based on radiological costs of $£ 9$ for each patient. Again, based on 1982 prices these figures would have been $£ 62400$ at $£ 13$ for each patient examined radiologically. Of these patients, 1501 were, however, categorised as "clinically positive"; the cost of radiographs for the 3328 "clinically negative" patients who developed an intracranial haematoma was therefore substantially less.

The reliability of computed tomography in detecting intracranial haematomas is well established but does not affect the dilemma of deciding which patients with mild injuries to admit to hospital. Rather, it poses a problem in deciding (in most parts of the country) which patients admitted to a primary surgical ward should be transferred to neurosurgical units for scanning and possible surgery. If more such patients were transferred to neurosurgical centres, and they were to arrive there sooner than usually happens at present, there would probably be an appreciable reduction in mortality and morbidity from intracranial haematoma. ${ }^{13}$ Selecting which patients with mild injuries should be admitted from accident and emergency departments, and which patients in primary surgical wards should be transferred for scanning, depends largely on identifying risk factors for the development of intracranial haematoma, the most important remediable complication. We are presently analysing data on large numbers of patients with recent head injuries to estimate the risk factors as a basis for evolving more effective but less costly policies than those now used in Britain. The present study confirms the findings of Totten and Buxton, ${ }^{6}$ which indicated that there was minimal risk in sending home patients from accident and emergency departments who were fully alert and orientated after recent head injury, even if they had a history of brief unconsciousness associated with post-traumatic amnesia for less than five minutes, provided that they did not have a skull fracture.

Our thanks to $\mathrm{Mr} \mathrm{J}$ Meagher who assisted with the coding of information. A D Mendelow, C Hessett, and J Bryden are supported by a head injury programme grant from the Medical Research Council to the Department of Neurosurgery, University of Glasgow. We wish to thank the consultants of the Department of Surgical Neurology, Edinburgh Royal Infirmary, for access to the hospital records of patients under their care.

Correspondence should be addressed to $\mathrm{Mr}$ A D Mendelow, Institute of Neurological Sciences, Southern General Hospital, Glasgow G51 4TF.

\section{References}

${ }^{1}$ Jennett B, MacMillan R. Epidemiology of head injury. Br Med 71981 ;282: $101-4$.

2 Field JH. Epidemiology of head injuries in England and Wales. London: HMSO, 1976.

${ }^{3}$ Strang I, MacMillan R, Jennett B. Head injuries in accident and emergency departments at Scottish hospitals. Injury 1978;10:154-9.

4 Galbraith S. Misdiagnosis and delayed diagnosis in traumatic intracranial haematoma. $B r M e d \mathcal{F} 1976$; i:1438-9.

5 Bartlett JR, Neil-Dwyer G. The role of computerised tomography in the care of the injured. Injury $1979 ; 11: 144-7$.

6 Totten J, Buxton R. Were you knocked out? Lancet 1979;i:369-70.

7 Scottish Home and Health Department. Scottish health services costs to March 1980. Edinburgh: SHHD, 1981.

${ }^{8}$ Cost of living indices. Prestel page 5511019. Croydon: Tolley Publishing, Oct 1982.

9 Jennett B, Murray A, Carlin J, McKean M, MacMillan R, Strang I. Head injuries in three Scottish neurosurgical units. Br Med f 1979;ii:955-8.

${ }^{10}$ Galbraith S, Mendelow AD, Jennett B. Skull fracture in head injury. Lancet 1981 ;ii:1350.

11 Royal College of Radiologists' Working Party. Costs and benefits of skull radiography for head injury. Lancet 1981 ;ii :791-5.

12 Galbraith S, Murray WR, Patel AR. Head injury admissions to a teaching hospital. Scot Med $\mathcal{F} 1977 ; 22: 129-32$.

${ }^{13}$ Teasdale G, Galbraith S, Murray L, Ward P, Gentleman D, McKean M. Management of traumatic intracranial haematoma. $\mathrm{Br}$ Med $\mathcal{F} 1982$ (in press).

(Accepted 14 September 1982)

HOREHOUND. There are two kinds of Horehound, the white and the black. The black sort is likewise called Hen-bit; but the white one is here spoken of.

Common Horehound grows up with square hairy stalks, half a yard or two feet high, set at the joints with two round crumpled rough leaves of a sullen hoary green colour, of a reasonable good scent, but a very bitter taste. The flowers are small, white, and gaping, set in a rough, hard prickly husk round about the joints, with the leaves from the middle of the stalk upward, wherein afterward is found small round blackish seed. The root is blackish, hard and woody, with many strings, and abides many years. It is found in many parts of this land, in dry grounds, and waste green places. It flowers in July, and the seed is ripe in August.

It is an herb of Mercury. A decoction of the dried herb, with the seed, or the juice of the green herb taken with honey, is a remedy for those that are short-winded, have a cough, or are fallen into a consumption, either through long sickness, or thin distillations of rheum upon the lungs. It helps to expectorate tough phlegm from the chest, being taken from the roots of Iris or Orris: It is given to women to bring down their courses, to expel the after-birth, and to them that have taken poison, or are stung or bitten by venomous serpents. The leaves used with honey, purge foul ulcers, stay running or creeping sores, and the growing of the flesh over the nails. It also helps pains of the sides. The juice thereof with wine and honey, helps to clear the eyesight, and snuffed up into the nostrils, purges away the yellow-jaundice, and with a little oil of roses dropped into the ears, eases the pains of them. Galen saith, it opens obstructions both of the liver and spleen, and purges the breast and lungs of phlegm: and used outwardly it both cleanses and digests. A decoction of Horehound (saith Matthiolus) is available for those that have hard livers, and for such as have itches and running tetters. The powder hereof taken, or the decoction, kills worms. The green leaves bruised, and boiled in old hog's grease into an ointment, heals the biting of dogs, abates the swellings and pains that come by any pricking of thorns, or such like means; and used with vinegar, cleanses and heals tetters. There is a syrup made of Horehound to be had at the apothecaries, very good for old coughs, to rid the tough phlegm; as also to void cold rheums from the lungs of old folks, and for those that are asthmatic or short-winded. (Nicholas Culpeper (1616-54) The Complete Herbal, 1850.) 